\title{
NO THEORY-FREE LUNCHES IN WELL-BEING POLICY
}

\author{
By Gil Hersch
}

Generating an account that can sidestep the disagreement among substantive theories of wellbeing, while at the same time still providing useful guidance for well-being public policy, would be a significant achievement. Unfortunately, the various attempts to remain agnostic regarding what constitutes well-being fail to either (a) be an account of well-being, (b) provide useful guidance for well-being policy, or (c) avoid relying on a substantive well-being theory. There are no theory-free lunches in well-being policy. Instead, I propose an intermediate account, according to which well-being is constituted by endorsed veridical experiences. This account refers back to theories of well-being but does so as agnostically as possible. An intermediate account of wellbeing is meant as a policy guiding compromise between the different theories of well-being that make claims regarding what constitutes well-being. An intermediate account does as well as can be hoped for in providing a basis for well-being policy.

Keywords: well-being; public policy; intermediate account; theory-free

\section{INTRODUCTION}

When policy-makers take it as one of their goals to implement policies that will improve people's lives, they might want to base their policy decisions on one of the many substantive theories of 
well-being available. ${ }^{12}$ But since reasonable people can disagree on what constitutes well-being, this would amount to policy-makers imposing their own views of the good life on others. In a liberal democracy imposing one's values on others is something we normally wish to avoid. Consequently, generating an account that can sidestep the disagreement among substantive theories of well-being as to what really constitutes well-being, while at the same time still providing useful guidance regarding well-being policy, would be a significant achievement.

In the first part of this article, I argue that any attempt to provide meaningful well-being policy advice while remaining agnostic regarding the correct substantive theory of well-being by avoiding any appeal to such theories will ultimately fail. ${ }^{3}$ To succeed in such an attempt would require that we treat something (revealed preferences for Hausman (2012), personal welfare values for Haybron and Tiberius (2015)) as indirect and imperfect evidence for well-being (Angner 2011). Of course, when trying to advise on well-being policy, neither indirectness nor imperfection are in themselves a problem. Even if an evidential or pragmatic account of well-being does not always get the right verdict on well-being, or does not do so directly, it can still be valuable for guiding well-being policy. Yet since these accounts require us to know which preferences are selfinterested, or which values are personal welfare values, we need a way to distinguish them from non-self-interested preferences or from other-regarding values. The problem arises because relying

\footnotetext{
${ }^{1}$ Some might accuse me of being overly naïve here in thinking that some policy-makers actually sincerely intend to improve people's lives. This might be true (although I doubt it). Nevertheless, if we only ascribe self-interested motivations to policy-makers, much of the discussion surrounding well-being policy is a moot point.

${ }^{2}$ Aiming to implement some policies that focus on well-being is a form of weak welfarism, since it takes it as reasonable that promoting people's welfare is one goal of public policy. Strong welfarism, by contrast, takes promoting people's welfare to be the sole goal of public policy. I take weak welfarism to be philosophically plausible, and a view various policy-makers have held (Bernanke 2012; Cameron 2010; Stiglitz, Sen, and Fitoussi 2009).

${ }^{3}$ By 'well-being policy' I mean policies aimed at improving the well-being of a group (e.g. citizens, residents, or some subset thereof), rather than a policy that targets groups at certain levels of well-being.
} 
on a substantive theory of well-being is ruled out, and an alternative is needed but is not to be had. Ultimately, there are no theory-free lunches in well-being policy.

Since we cannot achieve a completely theory-free account of well-being, in the second part of this article I offer an intermediate account as an alternative. ${ }^{4}$ On the intermediate account wellbeing is constituted by endorsed veridical experiences. This account does refer back to substantive theories of well-being but does this as agnostically as possible. An intermediate account of wellbeing is meant as a policy guiding compromise between the different theories of well-being that make claims regarding what constitutes well-being.

As I argue in (Hersch 2018), agreement on how to understand well-being in the public policy context is more likely than it is in the context of philosophical inquiry, since the domain of well-being in the public policy context is narrower than that of well-being in general. Such an account need not be correct in any strict sense, but merely useful in guiding and justifying choices regarding particular policies. It can miss a lot of the nuance that substantive theories of well-being capture. This lack of nuance entails that some things that some theories might want to take as relevant to well-being are missed. Yet because well-being policy has a lower bar of descriptive adequacy than do substantive theories of well-being that purport to be true, this is not too high a price to pay for an account that can deliver agreement on policy. This approach allows policymakers to remain agnostic regarding which substantive well-being theory is correct and still help guide well-being policies. An intermediate account does as well as can be hoped for in providing a justificatory basis for well-being policy.

\footnotetext{
${ }^{4}$ My intermediate account, as will be made clear in $\S$ III, takes a different approach from Alexandrova's mid-level theories (Alexandrova 2017). Alexandrova's mid-level theories act as midway between what she classifies as high theories and the actual well-being measures. Mid-level theories take high theories and apply them to particular kinds of people in particular kinds of circumstances.
} 


\section{WHY THEORY-FREE ACCOUNTS FAIL}

Having a theory-free account of well-being would be helpful since it makes it possible to justify well-being policy without taking a substantive stand on what the good life is. I am not the first to

find such an approach appealing, and several attempts have been made in different contexts to offer such a theory-free account (Hausman 2012; Haybron and Tiberius 2015; Wren-Lewis 2013; Taylor 2015). In this section I argue that a successful theory-free account of well-being for guiding well-being policy must jointly achieve several things: It must (a) be an account of well-being, (b) provide useful guidance for well-being policy, and (c) avoid relying on a substantive theory of well-being. Yet I argue that all attempts to achieve this have so far failed one way or another to deliver what we would hope for. Recognizing that these three requirements cannot be jointly satisfied should lead us to seek the requirement that we most likely should give up on if we nonetheless wish to implement well-being policy. In $\S$ III I argue that we must drop the requirement to avoid relying on substantive theories of well-being as it is usually understood, and instead I offer an account that does refer back to substantive theories of well-being. In doing so my intermediate account does not purport to be theory-free. Nevertheless, it succeeds as an account of well-being that can provide useful guidance for well-being policy, while minimizing its reliance on any one substantive theory of well-being. I now turn to discuss these requirements and how a purported theory-free account might fail.

\section{II.1 What it takes to be a successful policy-guiding theory-free account of well-being}

First, since the goal is to provide an account that can be useful for guiding well-being policy, we must be able to view the account as an account of well-being simpliciter. Yet the need for an account of well-being simpliciter does not mean that we must think that it is the true account 
of what constitutes well-being. Rather, we must have some reason to believe that the things the account tells us to promote do essentially promote well-being. We can have accounts of various things that are related to what we might think of as well-being, such as psychological well-being, economic well-being, or even health. However, the account we are in search for must be an account of overall well-being.

In her recent book, Alexandrova argues that the traditional goal philosophers have aimed at, that of providing an account of well-being simpliciter (what she calls the circumscription view), is neither shared by laymen and social scientists nor a fruitful goal (Alexandrova 2017). Alexandrova considers the circumscription view problematic because it neither fits with widespread use of the term, nor is required for making decisions that do not need to take all aspects of well-being into account at once. Instead, Alexandrova argues that we should understand wellbeing as arising in particular contexts, and that the content of well-being assertions needs to be indexed to specific circumstances. Nevertheless, because having an account of well-being simpliciter provides such a useful systemic understanding of all aspects of well-being, and because arriving at such an account has been a goal of philosophy for millennia, it is worthwhile to take this goal as seriously as we can before giving up.

Wren-Lewis, for example, argues that we can defend well-being policies without taking a substantive stand on what constitutes the good life if we view well-being as a primary good (WrenLewis 2013). On such a view, well-being, or more narrowly psychological well-being, is one of several primary goods that the state must provide its citizens as a prerequisite for them to be able to pursue whatever conception of the good they hold. This primary-good account gives us reason to promote well-being policies only insofar as they enable people to pursue their own aims. 
However, as Wren-Lewis himself makes clear, his argument at best supports treating only the psychological aspects of well-being as an instrumental good. In this way, Wren-Lewis' discussion veers away from an attempt to defend well-being policies at large and focuses instead on the narrower goal of defending psychological well-being policies aimed at promoting some psychological aspects such as life-satisfaction or affect. Even if we accept Wren-Lewis' defense of policies that promote psychological well-being, it does not function as a defense of policies that promote well-being generally. Since the goal of a theory-free account is to remain agnostic regarding what constitutes well-being, we cannot commit to the idea that well-being generally is equated with psychological well-being. As a result, Wren-Lewis' account fails as an account of well-being. 5

Second, the account must be able to provide useful guidance for well-being policy. Regardless of whether the account we use is descriptively adequate (it fits with our ordinary experience of well-being), the account must be normatively adequate in the sense that it is useful for guiding us in choosing well-being policies (Sumner 1996). The motivation for this article, and for similar work on the issue, is not only philosophical musings (important and interesting as they may be), but rather to provide some theoretical basis on which well-being policy can be chosen and defended. Consequently, any theory-free account that one provides must somehow be useful for well-being policy purposes. I am not so naïve as to believe that policy-makers interested in well-being policy will turn to philosophers for such guidance, so this is not a requirement for be useful in practice, though it would be nice if it were. However, the requirement is that a theoryfree account can, at least in principle, provide some guidance to potential policy-makers as to how to go about selecting their well-being policies.

\footnotetext{
${ }^{5}$ If Wren-Lewis does not intend for his account to be a theory-free account of well-being, then this is no criticism of him, merely a claim that his account does not succeed in doing something he does not intend it to do.
} 
Alexandrova is right that for most purposes we do not require anything beyond a concept of well-being in context. This is true for most policy contexts as well. However, once one looks high enough in the policy decision making chain of command, at some point some decisions do require an account of well-being simpliciter. Insofar as we ascribe to at least a weak form of welfarism, decisions, especially those that pertain to the proper allocation of resources between areas like health, education, defense, infrastructure, etc., requires having a conception of how these different areas compare with respect to their impact on well-being simpliciter. Perhaps the minister of education or the minister of health need not worry about how their respected ministries impact well-being relative to each other. But the prime minister, as well as the body that determines the national budget, require an account of well-being simpliciter insofar as they intend to allocate resources with some concern to how governmental policies impact individuals' well-being, rather than some aspect of well-being of some particular group of individuals.

Ideally, a theory-free account of well-being will provide guidance as to what the best single policy is in a given situation. But this is a very high bar of normative adequacy. It is probably an inappropriate bar to set for accounts of well-being. Only when one adds the input of empirical research, regarding both how policies affect people as well as what the background conditions actually are, is there any hope that an account can give such a specific recommendation. It might be the case, even then, that an account which unequivocally recommends a single policy is taking on more normative assumptions than we might be comfortable with. ${ }^{6}$

On the permissive end is the requirement that a theory-free account provide guidance on what policies are off the table. While not nearly as helpful as providing a single policy recommendation, theory-free accounts of well-being that can tell us which well-being policies are

\footnotetext{
${ }^{6}$ See some of the discussions on values in science and policy, e.g. (Kincaid, Dupré, and Wylie 2007).
} 
clearly off the table, do provide some guidance. In this sense, such accounts are normatively adequate. Nevertheless, this is a low bar of normative adequacy. Thus, when considering normative adequacy, it is appropriate not to imagine that what we face is a binary normatively adequate/inadequate criterion, but rather a spectrum of more/less normatively adequate. Accounts that can at most provide very little guidance, can be simply thought of as not normatively adequate.

Hausman's evidential account of preferences is an example of an account that passes only the most permissive normative adequacy test, and so we might consider it not to be normatively adequate. On Hausman's evidential account of preferences, people's choices can be taken as evidence for what is conducive to their well-being, but only when three assumptions hold:

(1) Individuals have true beliefs about what the feasible alternatives are.

(2) Individuals are competent evaluators of what is conducive to their well-being.

(3) Individuals' choices are aimed at promoting their own well-being.

How do we know when these assumptions hold without appealing to a substantive theory of wellbeing? Hausman turns to platitudes about well-being, which are supposed to help us discern the cases in which choices can be taken as evidence for what is conducive to well-being and cases in which they cannot. In this way Hausman's account avoids relying on any substantive theory of well-being, while supposedly giving us a reason to use people's choices to guide well-being policy.

As I have argued in (Hersch 2015), the problem is that Hausman's evidential account does not uniquely justify taking choices as evidence for well-being. Platitudes can also tell us that assumptions that justify treating other measures (e.g. subjective well-being (SWB) or capabilities) as evidence for what is conducive to well-being also sometimes hold. Consequently, instead of Hausman's evidential account uniquely justifying a reliance on choices as evidence when the assumptions hold, his evidential account justifies relying on any measure as evidence for what is conducive to well-being when the assumptions that justify relying on it hold. This is a problem 
because sometimes assumptions in support of different measures hold, yet the different measures point us to different policies. In such cases Hausman's evidential account gives us no guidance regarding which measure to use. Consequently, it gives us insufficient guidance regarding which policy to choose. Additionally, sometimes none of the assumptions hold, resulting in us having no justification for using any measure. Hausman's theory-free account lacks the resources to discriminate between measures that point to different policies. In such cases it is normatively inadequate and fails to provide sufficient guidance regarding well-being policy.

In another article Wren-Lewis adopts a similar approach to Hausman by relying on what he claims are widely accepted relationship between PWB (personal well-being, which includes both subjective well-being (SWB) and eudaimonic well-being (EWB)) and well-being (WrenLewis 2014). PWB tends to be a good indicator of well-being, people tend to care about their own PWB, and PWB tends to benefit people (cognitively and motivationally). Moreover, like Hausman, Wren-Lewis stresses that these relationships are defeasible and may not arise in certain contexts or conditions. This is the most one can say without a substantive theory of well-being. The problem for Wren-Lewis, as for Hausman, is that it leaves us no better off when we are faced with measures that point at different directions. Without having a way of knowing when one measure, PWB in Wren-Lewis' case, is a good measure of well-being, we cannot be sure that we should rely on PWB rather than, say, Hausman's preferences, as a measure of well-being. Since these measures do sometimes point us in different directions, we do sometimes need to know which measure to use. ${ }^{7}$ In such cases Wren-Lewis's account fails to provide guidance regarding policy choice.

\footnotetext{
7 Two well-known examples include, first Easterlin's claim that income and happiness diverge (Easterlin 1974). This claim is disputed by others (Hagerty and Veenhoven 2003; Stevenson and Wolfers 2008; Deaton 2008). A second example can be found in Kahneman's experience-based measure, which comes apart from memory-based
} 
Perhaps Wren-Lewis is aware of this shortcoming, since he says that it is possible to ask whether we have any reasons to doubt the relationship between PWB and well-being, and clarifies that 'these reasons are relatively theory-neutral' [emphasis added] (Wren-Lewis 2014: 34). Similarly, he later stresses 'this does not require a particular theory of well-being' [emphasis added] (Wren-Lewis 2014: 35). Such statements just make it clearer that what Wren-Lewis is looking for requires having some notion of well-being, even if a not very well-defined one. If this is the case, then Wren-Lewis's account fails as a theory-free account of well-being not because it is normatively inadequate, but because it relies on an account of well-being, albeit not a clear and explicit one. This is the third way a theory-free account of well-being can fail—by allowing a substantive theory of well-being to creep in. The whole point of a theory-free account of wellbeing is to be free of theory. If a substantive theory of well-being creeps in, then the account fails to provide the goods it promised.

\section{II.2 The unfulfilled promise of pragmatic subjectivism}

I have offered here several goals that a theory-free account of well-being for public policy must aim to jointly achieve and have provided examples of accounts that fail at achieving each. I now turn to discuss what I believe to be the most promising account-Haybron and Tiberius's pragmatic subjectivism. Haybron and Tiberius are clear on why their account is an account of wellbeing, nowhere in their account does a substantive theory explicitly creep in, and they are clear that they see this account as providing useful guidance to well-being policy. This account does not obviously fail to achieve any one of these goals. However, I argue that this is because Haybron 
and Tiberius's account is not fully developed and they leave some issues open. However one fills out their account, Haybron and Tiberius's pragmatic subjectivism cannot deliver what it promises.

According to Haybron and Tiberius, pragmatic subjectivism combines the claim that wellbeing policy should be subjective in practice with the claim that the relevant subjective element is the personal welfare values (PWV) people have. Well-being policy should in practice be subjective because it must be justifiable from the perspective of the intended beneficiaries. Well-being policy should focus on PWV because they are more robust pro-attitudes than preferences (both of which are subjective), and because they are focused specifically on the individuals' welfare rather than on their values more generally.

Haybron and Tiberius acknowledge that pragmatic subjectivism will not necessarily always lead to well-being policy that will promote what is actually good for people. Nonetheless, they argue that we have no epistemic access to what is actually good for people, and crowdsourcing individuals' own conception of well-being is the best way we have. ${ }^{8}$ As Haybron and Tiberius argue, all major theories agree on what things are most important for well-being, for most people, in practice. Moreover, most people tend to value these things as well. As a result, pragmatic subjectivism confines itself to issues on which many people share similar personal welfare values and on which all major theories of well-being agree. Indeed, confining their account only to these issues avoids the problems I go on to identify. But if we agree to limit well-being policy solely to these issues, we do not need Haybron and Tiberius's pragmatic subjectivist approach to being with. Any substantive theory of well-being would give us the right verdict, as long as we focus on those areas on which they agree.

\footnotetext{
${ }^{8}$ Haybron and Tiberius claim in their paper that much (though not all?) of the rationale for their account is that it exhibits 'deference to citizens' values in promoting their interest.' (Haybron and Tiberius 2015, 714).
} 
For pragmatic subjectivism to have added value, we need to view Haybron and Tiberius's pragmatic subjectivism as meant to go beyond those areas of agreement. The appeal of pragmatic subjectivism is that it is meant to get us past disagreements among competing substantive theories of well-being. An account that can do this can be genuinely useful for guiding well-being policy. But when we go beyond those things on which all major theories of well-being agree, things get tricky. Once we move beyond areas of general agreement we can more reasonably suspect that individuals' personal welfare values might be mistaken. But if we have no standard by which to judge whether these PWV are mistaken, we have no way to know that PWV are superior to other things, like the more standard preferences economists appeal to.

Where pragmatic subjectivism would be genuinely helpful is also where it faces two distinct but related problems. First, how do we distinguish between PWV and other kinds of values that individuals hold? Second, how can we be sure that these PWVs are generally a good proxy for well-being without appealing to a substantive theory of well-being?

To be useful, pragmatic subjectivism must give an account of how we distinguish between personal welfare values as opposed to values more generally (e.g. other-regarding values). Yet Haybron and Tiberius set this aside as a 'practical question regarding the application of pragmatic subjectivism and is best left for another occasion' (725). Since they think most of well-being policy deals with the most important PWV (e.g. health, enjoyment and freedom from suffering) and these are not difficult to classify, they need not be too worried about this problem. Yet as I discussed earlier, if this is all pragmatic subjectivism hopes to achieve, it is redundant, and any substantive theory can also give us similar verdicts about what Haybron and Tiberius consider the most important PWV. 
But it is hard to distinguish between PWV and values more generally whenever we look at anything beyond the obvious PWVs. Haybron and Tiberius explicitly wish to avoid a permissive approach to values that simply treats all values as evidence for well-being. They do so for reasons similar to standard objections to including all preferences as constituting well-being, including non-self-regarding ones. What other options are available to Haybron and Tiberius? They could follow Hausman's example and distinguish PWV from values generally similarly to how he distinguishes between relevant and irrelevant choices for guiding well-being policy. Focusing on choices (rather than values) Hausman treats as evidence of well-being only those choices that are made when several assumptions hold (true beliefs about the feasible alternatives, competency as evaluators of their own well-being, and a focus on promoting one's own well-being). While, as I argued earlier, this approach fails, it does make a genuine attempt to seriously tackle the issue.

How to distinguish PWV from values more generally is not merely a practical question to be addressed at a later date. If we are to evaluate whether PWVs can be considered acceptable evidence for well-being, we need to be able to determine which values are personal welfare values. Moreover, we need to be able to do this without taking a stand on what constitutes well-being. The options Haybron and Tiberius face are similar to those Hausman's account faces. Since they do not attempt to address the issue, it is impossible to say how Haybron and Tiberius fail.

But even if we could reliably distinguish between PWV's and values more generally, a second problem emerges. If we are to remain agnostic about which substantive theory of wellbeing is true, then we accept that we have no epistemic access to what is actually good for people. Haybron and Tiberius acknowledge that pragmatic subjectivism will not necessarily always lead to a well-being policy that will promote what is actually good for people. However, they believe that crowdsourcing individuals' own conception of well-being is the best evidence we have for 
what is good for people. While this all might be true, to claim that individuals' personal welfare values (PWV) 'tend not to be radically mistaken' requires some kind of yardstick. If we accept that PWV sometimes fail to successfully reflect well-being, we need a way of deciding when they are reliable and when they are not. If we think that PWV can always be relied on, then we are implicitly assuming a substantial subjectivist view, not merely a pragmatic one. We are in effect denying the possibility which objectivists take seriously, that people might mistakenly value things as constituting their welfare (e.g. avoiding medical treatment).

Haybron and Tiberius claim that '[e]ven with expert guidance, the possibility of error about the nature of wellbeing is substantial' (721). Yet the only way to be confident that this statement is true is by appealing to some yardstick that shows this. We must either implicitly assume some substantive theory of well-being, at the very least one that does not radically differ from individuals' personal welfare values, or else something else. Since Haybron and Tiberius could not be clearer that pragmatic subjectivism is not meant to be a substantive theory of well-being, they must be appealing to something else. What this something else is, though, is unclear.

Put simply and crudely the argument seems to amount to: 'We don't know what well-being is, but we know what people think it is. People are probably mostly right, let's go with what they say.' But without appealing to a substantive theory of well-being we have no warrant for thinking that people are probably mostly right. We are pretty sure that they are sometimes wrong. How then do we know when they are right and when they are wrong? We need a standard. If we don't want that standard to be a substantive well-being theory, we need something else. Haybron and Tiberius are mute on the issue.

The catchy claim that 'the epistemology of well-being favors pragmatic subjectivism', is incorrect (722). A more apt claim is that 'the epistemology of well-being has no favorites'. We do 
not have a way to entirely avoid discussions regarding substantive theories of well-being while at the same time being able to provide meaningful well-being policy recommendations. An evidential/pragmatic account cannot provide the theory-free lunch it intends to. Instead, in the next section I offer a different approach. While recognizing the importance of agnosticism in any account that is meant to guide well-being policy, it also recognizes the impossibility of remaining completely theory-free. Instead, the intermediate account relies on substantive theories of wellbeing, yet does this as agnostically as possible.

\section{AN INTERMEDIATE ACCOUNT OF WELL-BEING FOR POLICY}

In the previous section I argued that we cannot enjoy a theory-free lunch and that an approach that makes no appeal to theories of well-being cannot successfully justify and guide well-being policy. If we nonetheless wish to provide any recommendations regarding well-being policy while remaining as agnostic as possible, we must accept that some appeal to well-being theories is necessary. However, just because we must appeal to well-being theories to do well-being policy, it does not follow that we cannot remain agnostic on the question of what is the correct particular substantive theory of well-being. In this section I propose a way of doing just that. I propose an intermediate account of well-being for policy purposes that distills the 'hard core' of each of the central theories of well-being under consideration, and articulates them in terms of requirements that the intermediate account must fulfill. As a result, according to the intermediate account, wellbeing is constituted by endorsed veridical experiences.

Adopting Taylor's (2015) conception of well-being markers allows us to discuss different factors that are relevant to well-being without taking a stand on their precise relationship to well- 
being and which substantive well-being theory is correct. ${ }^{9}$ Perhaps different theories will disagree on whether health constitutes, promotes or is an indicator of well-being, but they might agree that health is, more broadly, a marker of well-being. Thinking of well-being markers makes it possible to begin framing the agnostic approach of the intermediate account. This intermediate account borrows from Lakatos's discussion of research programmes (Lakatos 1970). According to Lakatos, scientific research programmes are comprised of a hard core and a protective belt of auxiliary hypotheses. The hard core of the programme is 'irrefutable' by the 'methodological decisions of its protagonists.' The protective belt consists of a set of auxiliary hypotheses that are the "refutable variants' of the research-programme' (135). Lakatos explains that '[i]t is this protective belt of auxiliary hypotheses which has to bear the brunt of tests and get adjusted and readjusted, or even completely replaced, to defend the thus-hardened core' (133). Lakatos discusses Newton's three laws of dynamics and his law of gravitation as an example of a research programme's hard core. Newton's auxiliary assumptions included planets that are mass-balls, interplanetary forces, spinning balls, wobbles and bulging planets. Nevertheless, anomalies and counter-evidence, according to Lakatos, are never completely exhausted and can only be digested piecemeal by a research programme.

We can similarly conceive of philosophical theories of well-being as consisting of a combination of a hard core of the programme and a protective belt. This way of conceptualizing well-being theories guides the generation of the intermediate account of well-being I offer. It

\footnotetext{
${ }^{9}$ Taylor builds on Crisp's explanatory-enumerative distinction (Crisp 2006). According to Crisp, something can be constitutive of well-being - something that constitutes well-being, or it can be productive of well-being - something that is a reliable means of achieving and promoting well-being. To these Taylor adds a third category - an indicator of well-being, which neither constitutes nor promotes well-being, but nevertheless correlates with well-being and so can serve as an indicator of whether something else promotes well-being. One problem with Taylor's approach is that although it can generate broader agreement among well-being theories, the indicator category raises standard questions from philosophy of science regarding the relationship between correlation and causation. If there is no claim that indicators are causally related to well-being, we have no reason to believe that if we devise policy and act on it the established correlation will not break down.
} 
requires distilling the hard core of each of the central theories of well-being under consideration from its protective belt and articulating it in terms of a requirement that the intermediate account must fulfill. I take the hard core to be what the proponents of different well-being theories are most committed to, while the protective belt is the amalgamation of hypotheses required to make the theory descriptively adequate.

Without a sufficiently well-articulated protective belt, a well-being theory would be too abstract to be able to provide any explicit claims about particular cases, and thus not sufficiently descriptively adequate. However, since for some ways of construing the protective belt a counterexample might be offered to the theory, the protective belt is sufficiently disposable as to replace it with one that the counterexample no longer works. For example, a simple desirefulfilment theory that takes the fulfilment of actual desires as constituting well-being faces challenges from cases in which we have a genuine desire for something, which seems to everyone (including our reflective selves) to be bad for us, as would be the case if we had a desire for a food that we are allergic to. The protective belt of actual desires can be easily replaced with a protective belt of idealized desires, rendering the counterexample ineffective.

The protective belt can be thought of as way theories try to make sure they are descriptively adequate. But getting rid of it allows the theory to be normatively adequate. This is a fair tradeoff when what guides our endeavor solely is normative adequacy. By getting rid of the protective belt the theory is striped from the various supporting hypotheses and stipulations that help make the theory a palatable one from the perspective of how well it abides by our conceptions of well-being. But recognizing that people differ in their conception of the good requires that for policy purposes, we pay less attention to the theory's descriptive adequacy. That a theory is committed to fewer claims reduces its level of specificity, but it does not make it any less 'correct'. However, stripping 
the theory of specificity allows it to exhibit more agreement with other theories that have other, different, hard cores.

This is in a sense a reverse engineering of theories of well-being that were designed in a way that makes them descriptively adequate. The reason to do this is to generate more conceptual space for agreement among different theories of well-being in order for them to be more jointly palatable as normatively adequate theories. By narrowing the theoretical commitments of each of the different theories of well-being to their hard core, there are fewer issues on which to disagree. This does not entail that there will, in fact, be less disagreement, merely that when focusing only on the hard core of each substantive well-being theory, the logical space for things to disagree on is reduced. Theories of well-being have more to them than a single requirement at their core. Because theories are so rich, focusing on a single requirement to represent whole types of theories will lose some of the philosophically interesting variations that exist. This is unavoidable. Whether it is a problem for an account of well-being that is meant to be adequate for guiding measure choice for public policy is a different matter.

Consider the following analogy. Amy, Ben, and Casey each have a favorite sport. Amy is basketball fan, Ben is a tennis fan, and Casey prefers relay racing. It isn't clear how they can come to an agreement on what to watch on TV. However, when prodded as to why they enjoy their respective sport, Amy answers that this is because she loves games with balls, Ben responds that he enjoys games with no physical contact, and Casey considers team sports to be superior. Each of these three positions are the hard core of each person's sporting commitments. Since these are the things each person is committed to, we can accommodate their individual desires for a non- 
contact team sport with a ball and achieve a level of agreement regarding what to watch on TV by offering that they watch volleyball. ${ }^{10}$

This intermediate account is not meant to be true of well-being, merely useful for guiding choices of well-being measure for public policy. ${ }^{11}$ This account relies on two conditions that have already been flagged in the literature - experience and preference (Woodard 2012). To these two conditions I add a third condition—existence — as a candidate for adding the agreement of the proponents of objective-lists. These are the three requirements, each representing a family of theories, that jointly make up the intermediate account:

Experience - for any subject S, the only constituents of S's welfare are S's experiences Endorsement - for any subject S, the only constituents of S's welfare are the occurrence of some set of states that $\mathrm{S}$ endorses

Existence - for any subject S, the only constituents of S's welfare are some set of actual occurrences

I turn to discuss each requirement in turn.

\section{III.1 The Experience Requirement}

Griffin (1986) argues that any theory of well-being must meet an experience requirement when criticizing desire-satisfaction accounts of well-being, and in particular informed-desire accounts. Griffin takes the breadth of desire-satisfaction accounts as one of their central flaws. Well-being, on such accounts, can be influenced not only by things that we are unaware of, but also by things that do not affect our lives in any way. According to Griffin, '[t]he trouble is that one's desires

\footnotetext{
${ }^{10}$ In order to avoid any misunderstandings, the people and their preferences for a particular sport are meant to be analogous to theories of well-being.

${ }^{11}$ Perhaps other intermediate accounts that set the point of compromise elsewhere than this one might be superior in different ways. Once there is agreement on the usefulness of an intermediate account, there is a second question of whether the particular intermediate account I propose is the best available. Making the case for this particular intermediate account as superior to all others is beyond the scope of this article. Moreover, as it is the only intermediate account currently in the literature, only through other's proposing plausible alternatives and examining their strengths and weakness will it make sense to judge whether the intermediate account I offer is the best.
} 
spread themselves so widely over the world that their objects extend far outside the bound of what, with any plausibility, one could take as touching one's own well-being' (17).

Griffin thinks we need an experience requirement to limit the scope of what can be considered as affecting our well-being only to those things that we experience. Without such requirement, the well-being of those who died can be influenced by things still occurring, which he takes to be a problem. Griffin argues that the need for any desire-satisfaction account to introduce some experience requirement to avoid arbitrariness entails a loss of breadth, something that made such accounts attractive to begin with.

Along similar lines Scanlon (1993) argues that an experience requirement is needed to preserve the idea that improvements in well-being have positive ethical value. If experience was not inherent to well-being, it isn't clear why a person's well-being places on us any moral demands. As Scanlon argues, it seems implausible that we can have any prima facie obligation to improve an individual's well-being if it is affected by changes in spatio-temporally distant states of affairs (like a change in the color of Uranus in the year 20,000 AD).

Griffin does worry that the experience requirement might go too far by banning things that are included in our ordinary notion of well-being, such as accomplishments and authentic personal relationships (19). Yet Griffin is wrong to worry. The experience requirement merely excludes accomplishments and authentic relationships that bear nothing on experience. If, for example, a researcher's work makes possible the discovery of a cure for some disease, but the researcher is unaware of this fact and so does not recognize the accomplishment as such, it would not count as an experience and would not count as conducive to her well-being. But, contra Griffin, this sounds reasonable to me. 
More problematic are distinctions between conscious mental-states and nonconscious ones. It might seem plausible that some pleasant scent in a room causes someone to be less stressed, though it is then not clear whether this counts as a mental-state and whether it counts as an experience, if the person is unconscious of it as such. The experience requirement of course does not capture all that mental-states theories consider important to well-being, as it takes no stand on what kind of experiences count as conducive or harmful to well-being, merely that they must be experiences. Specific theories, such as hedonism, narrow things down to pleasures and pains, though there are a variety of ways to cash these out as well. Nevertheless, the experience requirement captures a central aspect of mental-states theories.

Potential objections to an experience requirement notwithstanding, it is clear that the different versions of mental-states theories share in common a commitment to the idea that whatever contributes to one's well-being, it must have an effect on what 'happens in the head'. The individual's mental-states must in some way be affected for there to be an impact on her wellbeing, and so she must have an experience for something to count as impacting well-being. As Nozick's experience machine thought experiment shows, this experience can be wholly internal to the person, with no manifestation in the external world (Nozick 1974). Nevertheless, this would count as an experience of hers. A requirement that can embody what this family of well-being theories - mental-states theories — is that a person's experience be a marker of well-being.

Woodard (2012) formalizes the experience requirement and states that '[a] theory accepts the experience requirement just in case it claims that, for any subject $\mathrm{S}$, the only constituents of S's welfare are S's experiences' (795). Woodard is clear that for a theory to reject the experience requirement does not mean that it rejects experiences as relevant to well-being. Experiences might 
still play a role in well-being, it would simply not be the case that experience is a necessary condition for well-being.

Thus, experience can be construed as the 'hard core' of mental-states accounts. To represent this central commitment of mental-states theories we can formulate the experience requirement as:

Experience - for any subject S, the only constituents of S's welfare are S's experience.

\section{III.2 The Endorsement Requirement}

The second family of theories of well-being I examine is preference-satisfaction, or desirefulfilment, theories of well-being. Preference-satisfaction theories can vary widely. How preferences are construed and what their satisfaction entails is open to different ways of articulating the theory. These can be revealed preferences (as economists use the term), actual preferences, or ideal preferences ('ideal' can then be construed in different ways). Preferences can be limited to self-interested preferences as well as limited only to forward looking preferences. The satisfaction of preferences can be thought to occur when the individual believes it does, when there is an actual change in the state of the world, when there is a change in the world and the individual knows about it, or only when the preference is satisfied and the individual still holds the relevant preference. These are all different variants of preference-satisfaction theories of well-being.

What, then, is the underlying unifying hard core that is shared among all preferencesatisfaction theories of well-being? Using Lakatos's terminology, it is clear that the hard core of preference-satisfaction theories is that well-being is constituted by preferences or desires, however understood, being satisfied or fulfilled in some way. This is intentionally vague, as it is the auxiliary assumptions in the protective belt that do the work of fleshing out this core idea. How 
preferences are construed and what their satisfaction entails is open to different ways of articulating the theory.

Since we are willing to view desires so broadly, it might be more appropriate to describe the hard core not as involving the satisfaction of desires, but the occurrences of states of the world that a person endorses. Endorsement is more general than either preferences or desires in that at a minimum it merely requirements some approval of the state of the world to make that conducive to the person's well-being. Such an approval need not manifest itself in desires or preferences, which, however understood, seem to be a subset of endorsement. ${ }^{12}$

An endorsement requirement might seem less intuitive than the experience requirement. For those who do not hold a preference-satisfaction theory of well-being, it seems plausible that something might be conducive to an individual's well-being, despite that individual not wanting/desiring/endorsing that good. This view is how we think of the well-being of children, but it also guides forms of paternalism. If something cannot in principle be good for us without us endorsing it, then paternalism (understood as making someone do something that is good for them against their will) is an oxymoron. ${ }^{13}$

Even if many might view preference-satisfactions theories of well-being as implausible, there are many who think them a good account of what constitutes well-being. To get at this family of theories as broadly as possible, endorsement can be construed as the 'hard core' of preferencesatisfaction accounts. To represent this central commitment of preference-satisfaction theories we can formulate the endorsement requirement as Woodard does, albeit with a slight tweak — using endorsement rather than desires:

12 Tiberius (2018) takes a similarly broad notion of value fulfillment as her focus.

13 This assumes a variety of conditions hold, such that we know about the good, act on the endorsement, etc. 
Endorsement - for any subject S, the only constituents of S's welfare are the occurrence of some set of states that $\mathrm{S}$ endorses

Woodard does provide a useful way of categorizing theories of well-being. Yet relying only on his two conditions is not sufficient for my purposes in this article. To create a plausible intermediate account I need a requirement that represents the hard core of each family of theories. Thus, I need a third requirement that covers theories that neither require experience nor endorsement for well-being, but rather something else. However, as Woodard explains, his forth category does not merely contain standard objective-list theories, it contains all theories that do not share either of the two before mentioned requirements. This includes perfectionist theories, bare-objective-list theories, capabilities accounts, and any other theories that does not fit neatly with the two requirements mentioned thus far. I now turn to formulate a requirement to represent the hard core of these theories.

\section{III.3 The Existence Requirement}

While preference-satisfaction and mental-states theories have a fairly recognizable hard core that is common to each family of theories, this is not true for objective-list theories and for the third requirement of the intermediate account. The diversity of such theories poses the biggest challenge to the intermediate account, since for it to be useful it needs also to distill a central requirement for objective-list theories. Coming up with a requirement that represents the hard core of such an eclectic list is not easy. A first proposal for a hard core for objective-list theories is an objective good requirement:

Objective Good - for any subject S, the only constituents of S's welfare are some set of states that are objectively good for $\mathrm{S}$. 
This requirement does manage to include a wide swath of objective-list theories, ranging from a Bare-Objective-List (BOL) theory (Arneson 2016), to perfectionist theories (Hurka 1993), to the capabilities approach (Sen 1987; Nussbaum 2000). Yet while this requirement might be at the hard core of all theories that do not have some kind of experience or endorsement criteria, it is question begging. It is question begging because according to this requirement what is good for $\mathrm{S}$ is what is objectively good for her. Another way to put it is that what is good for S is what is good for S regardless of S's preferences and experiences. But if we were at all clear as to what is objectively good for people, we would not need an intermediate account to begin with.

A requirement that does not suffer from such circularity, though it is very restrictive, is an excellence requirement:

Excellence - for any subject S, the only constituents of S's welfare are some set of excellences for $\mathrm{S}$

An excellence requirement is not circular as it makes welfare conditional on a person's excellences. This requirement successfully captures Aristotelean and perfectionist views of wellbeing. On such views there are properties that are essential to humans qua humans, and that the good life consists in a maximal development of these properties (Hurka 1993). An excellence requirement also captures some versions of the capabilities approach, most notably Nussbaum's. According to Nussbaum, certain functions are typically understood as the mark of the presence of human life and a mark of being distinctively human, and pursuing one's own well-being is an expression of our powers of self-definition (Nussbaum 2011). Specifically, practical reason and affiliation are the two functionings that must be actualized for a person to manifest her humanity, because 'they both organize and suffuse all the others, making their pursuit truly human' (92). 
However, an excellence requirement would exclude both Arneson's BOL and Sen's Capabilities Approach, which do not take the things on an objective-list to have anything to do with excellences. The BOL merely consists of a list of things that are objectively good for individuals to attain more of, without any regard for excellence in any way. Sen's Capabilities Approach takes 'functionings', which are 'an achievement of a person: what he or she manages to do or be', as central (Sen 1987: 7). An individual can jointly achieve different combinations of functionings, and each of these combinations of functionings can be viewed as a 'capability set'. As a simplistic example, consider a person who has a gallon of gas. She can either drive her car thirty miles, keep herself warm for three hours or nourish herself with two dollars' worth of food, each being a single functioning. ${ }^{14}$ Yet she cannot do all three with one gallon of gas. Such a person would have multiple capability sets, each corresponding to one of these functionings fully fulfilled, as well as capability sets corresponding to the achievement of various combinations of partially fulfilled functionings. The combination of all the capability sets taken together is the person's 'capabilities set'. This is a set of sets and represent all the various ways in which a person can combine the commodities under her control into actualized functionings. Sen's Capabilities Approach, like Arneson's BOL, would not be represented by a requirement that takes excellence as its central feature. Since these are two significant views in the well-being literature, they are worth taking seriously when trying to construct an intermediate account of well-being.

A requirement that both avoids circularity but is also inclusive of all objective-list theories, is an existence requirement:

Existence - for any subject S, the only constituents of S's welfare are some set of actual occurrences

\footnotetext{
${ }^{14}$ What constitutes a functioning is left under-described by Sen, though each of these seem to potentially count as a functioning.
} 
What is it that must actually occur in the world for something to constitute S's welfare is obviously open to a wide swath of interpretations. However, as argued earlier, there is a wide range of objective-list theories available. The existence requirement is meant to ground well-being in 'objective' reality. Such a requirement would reject the possibility of well-being increasing through false beliefs of any kind, including experience machines, mistakes, and adaptation. The existence requirement tells us that what can be considered well-being influencing must exist regardless of whether we want it or experience it. I take this to be the hard core of objective-list theories. This is especially salient when objective-list theories are juxtaposed to mental-states and preference-satisfaction theories of well-being.

While an existence requirement might seem weak to some, it is not vacuous. The existence requirement precludes false beliefs that might give rise to an individual being happy or the illusion that her preferences were satisfied. But the existence requirement also precludes welfare nihilism, according to which there are no constituents of welfare. If any theory relies on an existence requirement then it does not cohere with welfare nihilism. Since the intersection of any theory of well-being (other than welfare nihilism) with welfare nihilism is an empty set, to have welfare nihilism taken as another requirement for an intermediate account would be counterproductive.

By supplementing Woodard's taxonomy with a third requirement-an existence requirement-we can generate an intermediate account of well-being that generates some agreement among at least three families of theories of well-being: preference-satisfaction, mentalstates and objective-list. Ultimately, my intermediate account does not substantially differ from what Sumner viewed as a desired experience theory according to which ' $\mathrm{x}$ makes me better off (directly or intrinsically) just in case (1) I desire x, (2) x occurs, and (3) I am at least aware of x's occurrence' (Sumner 1996: 127). Such a combination would yield an account that is at the 
intersection of a desire-satisfaction theory and a mental-states theory. This would significantly limit what can count as conducive to well-being from what each of theories would count as conducive to well-being on its own. The difference lies, however, in what we take our accounts to be doing. While Sumner views this as a reasonable account of what actually constitutes well-being, I am not so ambitious. My intermediate account is meant as a solution to the challenge faced by the need for basing well-being policy on some account of well-being while remaining as agnostic as possible about what actually constitutes well-being. The intermediate account discussed here succeeds in doing this.

\section{IIII. FROM A WELL-BEING ACCOUNT TO A WELL-BEING MEASURE TO WELL-BEING POLICY}

I have argued in this article that it would be very helpful for policy-makers if we could devise an account of well-being to guide well-being policy that does not need to refer to any substantive theory of well-being. Despite our sincere wishes to arrive at such an account, I argued that such an account is not to be had. I argued that a successful theory-free account of well-being for guiding well-being policy must jointly achieve several things: It must (a) be an account of well-being, (b) provide useful guidance for well-being policy, and (c) avoid relying on a substantive theory of well-being. The most promising account, Haybron and Tiberius's pragmatic subjectivism, is promising because it is not fully worked out. Once we try to do this, we find that it cannot deliver a theory-free account that gives useful guidance in the domains of policy in which it is most needed.

Instead, I offered another approach, one that succeeds as an account of well-being that can provide useful guidance for well-being policy. While it refers back to substantive theories of well- 
being, it does so in as agnostic a way as possible. On this intermediate account well-being is constituted by endorsed veridical experiences. This is a way of characterizing well-being for policy purposes that is comprised of each theory's central requirement, respects these central requirements, and so ought to be plausible to that theory. There can still be disagreement between the intermediate account and the substantive theories it is based on. But, this disagreement should not be too big a pill for the proponents of any of the substantive theories to swallow. While the theoretical disagreement is not put to rest, reasonable compromise is achieved.

While not my central aim, I believe that the approach offered in this article also has the potential to influence the philosophical debate regarding the nature of well-being. The traditional philosophical approach that seeks to defends one's chosen theory from criticism while offering criticisms of other theories, while fruitful in its own right, is not the only approach one can take in the well-being debate. Instead, seeking common ground among different theories of well-being, attempting to understand what their central commitments are and how they can be accommodated, and being clear on what domains give rise to more or less agreement among the different theories, can be fruitful avenues of well-being research.

The intermediate account of well-being merely tells the policy-makers what things they should care about, but a measure is needed to then gauge which policy options best achieves those things. We thus need to look at the different measures available in light of the intermediate account. Is there a measure that is the best operationalization of the intermediate account? Do we have a substantive account for why a given measure should be used? Currently, I believe the answer to both is no. But having a way of characterizing well-being that can be accepted by proponents of the different theories of well-being is a first step. The intermediate account I proposed can be used by those working on creating, operationalizing, and refining well-being measures to construct a 
measure. The way this intermediate account was set up, I speculate that the most promising measure will be an index consisting of a measure that corresponds to each requirement. Is this the best way to go? Here the characterization work ends here and the operationalization work begins. ${ }^{15}$

Virginia Tech, USA

\section{REFERENCES}

Alexandrova, A. (2017) A Philosophy for the Science of Well-Being. Oxford: Oxford University Press.

Angner, E. (2011) 'Are Subjective Measures of Well-Being 'Direct'?', Australasian Journal of Philosophy 89/1: 115-30.

Arneson, R. (2016) 'Does Fairness Require a Multidimensional Approach?', In M. Adler and M. Fleurbaey (eds.) The Oxford Handbook of Well-Being and Public Policy. Oxford: Oxford University Press.

Bernanke, B. (2012) 'Economic Measurement', in 32nd General Conference of the International Association for Research in Income and Wealth. Cambridge MA. <www.federalreserve.gov/newsevents/speech/bernanke20120806a.htm.> accessed 18 April 2019.

Cameron, D. (2010) PM Speech on Wellbeing. London, UK. <www.gov.uk/government/speeches/pm-speech-on-wellbeing> accessed 18 April 2019.

\footnotetext{
${ }^{15}$ This paper was significantly improved thanks to discussions and feedback from several individuals. I thank Craig Agule, Anna Alexandrova, Richard Arneson, Saba Bazargan-Forward, Craig Callender, Nancy Cartwright, Tyler DesRoches, Mark Fabian, Alexandre Marcellesi, Casey McCoy, Michael Moehler, Thomas Rowe, Eran Tal, Valerie Tiberius, Gregory Whitfield, and two anonymous referees for comments on earlier drafts. I also thank audiences at the 2017 Philosophy of Social Science Round Table, the 2018 Mississippi Philosophical Association Well-Being Conference, and the 2018 Inter-University Centre Dubrovnik Annual Philosophy of Science Conference.
} 
Crisp, R. (2006) Reasons and the Good. Oxford: Oxford University Press.

Deaton, A. (2008) 'Income, Health, and Well-Being around the World : Evidence from the Gallup World Poll', The Journal of Economic Perspectives, 22/2: 53-72.

Easterlin, R. (1974) 'Does Rapid Economic Growth Improve the Human Lot? Some Empirical Evidence', Nations and Households in Economic Growth, 89: 89-125.

Griffin, J. (1986) Well-Being: Its Meaning, Measurement and Moral Importance. Oxford: Clarendon Press.

Hagerty, M. and R. Veenhoven (2003) 'Wealth and Happiness Revisited', Social Indicators Research 64/April: 1-27.

Hausman, D. (2012) Preference, Value, Choice, and Welfare. Cambridge: Cambridge University Press.

Haybron, D. and V. Tiberius (2015) 'Well-Being Policy: What Standard of Well-Being?', Journal of the American Philosophical Association, 1/4: 712-33.

Hersch, G. (2015) 'Can an Evidential Account Justify Relying on Preferences for Well-Being Policy?', Journal of Economic Methodology, 22/3: 280-91.

— . (2018) 'The Narrowed Domain of Disagreement for Well-Being Policy”, Public Affairs Quarterly, 32/1: 1-19.

Hurka, T. (1993) Perfectionism. Oxford: Oxford University Press.

Kincaid, H., J. Dupré, and A. Wylie, (eds.) (2007) Value-Free Science?: Ideals and Illusions. Oxford: Oxford University Press.

Lakatos, I. (1970) 'Falsification and the Methodology of Scientific Research Programmes', In I. Lakatos and A. Musgrave (eds.) Criticism and the Growth of Knowledge, 91-197. Cambridge: Cambridge University Press. 
Nozick, R. (1974) Anarchy, State and Utopia. New York: Basic Book.

Nussbaum, M. (2000) Women and Human Development: The Capabilities Approach.

Cambridge: Cambridge University Press.

. (2011) Creating Capabilities: The Human Development Approach. Cambridge:

Harvard University Press.

Redelmeier, D. and D. Kahneman (1996) 'Patients' Memories of Painful Medical Treatments:

Real-Time and Retrospective Evaluations of Two Minimally Invasive Procedures', Pain, 66: $3-8$.

Scanlon, T. (1993) 'Value, Desire, and Quality of Life', In M. Nussbaum and A. Sen (eds.) The Quality of Life, 185-200. Oxford: Oxford University Press.

Sen, A. (1987) Commodities and Capabilities. New Delhi: Oxford University Press.

Stevenson, B. and J. Wolfers (2008) 'Economic Growth and Subjective Well-Being :

Reassessing the Easterlin Paradox', Brookings Papers on Economic Activity, 2008: 1-87.

Stiglitz, J., A. Sen, and J. Fitoussi (2009) Report by the Commission on the Measurement of Economic Performance and Social Progress.

Sumner, L. (1996) Welfare, Happiness \& Ethics. Oxford: Clarendon Press.

Taylor, T. (2015) 'Towards Consensus on Well-Being', in J. Søraker et al. (eds.) Well-Being in Contemporary Society, 1-16. Springer.

Tiberius, V. (2018) Well-Being as Value Fulfillment: How We Can Help Others to Live Well. Oxford: Oxford University Press.

Woodard, C. (2012) 'Classifying Theories of Welfare', Philosophical Studies, 165/3: 787-803. Wren-Lewis, S. (2013) 'Well-Being as a Primary Good: Towards Legitimate Well-Being Policy', Philosophy \& Public Policy Quarterly, 31/2: 2-9. 
—. (2014) 'Towards a Widely Acceptable Framework for the Study of Personal WellBeing', in J. Søraker et al. (eds.) Well-Being in Contemporary Society, 17-38. Springer. 